\title{
RESEARCH
}

\section{Incident atrial fibrillation in patients with differentiated thyroid cancer: a meta-analysis}

\author{
Georgios Kostopoulos1,*, Ioannis Doundoulakis 2,3,*, Christina Antza4,5, Emmanouil Bouras ${ }^{6}$, \\ Krishnarajah Nirantharakumar7, Dimitrios Tsiachris ${ }^{3}$, G Neil Thomas7, Gregory Y H Lip ${ }^{8,9}$ and \\ Konstantinos A Toulis ${ }^{1,7}$
}

1Department of Endocrinology, 424 General Military Hospital, Thessaloniki, Greece 2Department of Cardiology, 424 General Military Hospital, Thessaloniki, Greece ${ }^{3}$ Athens Heart Center, Athens Medical Center, Athens, Greece

${ }^{4} 3^{\text {rd }}$ Department of Internal Medicine, Aristotle University, Hypertension, Hypertension-24h ambulatory blood pressure monitoring center, Papageorgiou Hospital, Thessaloniki, Greece

IInstitute of Metabolism and Systems Research, University of Birmingham, Birmingham, UK

${ }^{6}$ Laboratory of Hygiene, Social \& Preventive Medicine and Medical Statistics, School of Medicine, Faculty of Health Sciences, Aristotle University of

Thessaloniki, University Campus, Thessaloniki, Greece

7Institute of Applied Health Research, University of Birmingham, Birmingham, UK

${ }^{8}$ Liverpool Centre for Cardiovascular Science, University of Liverpool and Liverpool Heart \& Chest Hospital, Liverpool, UK

9Department of Clinical Medicine, Aalborg University, Aalborg, Denmark

Correspondence should be addressed K A Toulis or G Y H Lip: info@toulis.gr, Gregory.Lip@liverpool.ac.uk

*(G Kostopoulos and I Doundoulakis contributed equally to this work)

\begin{abstract}
Differentiated thyroid cancer (DTC) represents the most common form of thyroid neoplasms and is becoming increasingly prevalent. Evidence suggests a possible relationship between DTC diagnosis and subsequent atrial fibrillation (AF). If confirmed, this may present an alarming health risk (AF) in an otherwise condition with a relatively good prognosis (DTC). The aim of this systematic review and meta-analysis is to provide for the first time a pooled estimate of AF incidence in DTC patients in comparison to healthy controls. A detailed search in electronic databases, clinical trial registries and grey literature was performed to identify studies reporting the incidence of AF in DTC patients. Newcastle-Ottawa quality assessment scale was used to assess study quality. We used a random effects (RE) generalized linear mixed model (GLMM) in pooling of individual studies and also calculated a prediction interval for the estimate of a new study. Six observational studies met the eligibility criteria, which included totally 187,754 patients with DTC and 199,770 healthy controls. The median follow-up period was 4.3 to 18.8 years; the incidence rate of AF was $4.86\left(95 \% \mathrm{Cl}, 3.29\right.$ to $\left.7.17, \mathrm{I}^{2}=96 \%\right)$ cases per 1000 person-years, while the incidence rate ratio was $1.54\left(95 \% \mathrm{Cl}, 1.44\right.$ to $1.65, \mathrm{I}^{2}=0 \%, 95 \% \mathrm{PI}$, 1.33 to 1.78 ). This is the first meta-analysis to confirm that patients with DTC are at a high risk for developing AF, which may be attributed to a state of iatrogenic hyperthyroidism due to long-term thyrotropin suppression therapy.
\end{abstract}

(c) 2021 The authors Published by Bioscientifica Ltd. Printed in Great Britain

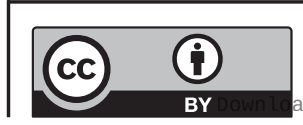

This work is licensed under a Creative Commons Attribution 4.0 International License. 


\section{Introduction}

Differentiated thyroid cancer (DTC), which includes papillary (85\%) and follicular (12\%) cancer, represents the most common form of malignant thyroid neoplasms. The age distribution is binomial (first peak at 35-40 years old, second peak over 70 years) with a consistent female preponderance (Rahbari et al. 2010, DeSantis et al. 2014). DTC is becoming increasingly prevalent, which is largely attributable to the increased detection of small papillary thyroid carcinomas and might be related to the widespread use of neck ultrasonography and/or cytological analysis of fine-needle aspirations (Davies \& Welch 2014, Li et al. 2020). Thus, a timely diagnosis of the disease is common, so that an appropriate therapy is often instituted early, leading to a decrease in the disease-specific mortality rates since 1970s (https://www.cancerresearchuk.org/healthprofessional/cancer-statistics/statistics-by-cancer-type/ thyroid-cancer/mortality; accessed (September) (2020)). In all, DTC has a favourable prognosis and, therefore, long-term survival is expected (DeSantis et al. 2014, Viola et al. 2016).

Total thyroidectomy is the cornerstone of initial management with or without adjuvant radioiodine-131 ablation (RAI). According to the European and American Thyroid Association, long-term levothyroxine suppression of thyrotropin (THST) is recommended in high- and selected intermediate-risk patients, whereas a low-normal thyroid-stimulating hormone (TSH) is considered to be the optimal therapeutic target for low-risk patients (Perros et al. 2014, Haugen et al. 2016). The rationale behind this approach is the minimization of potential TSH-mediated stimulation of tumour growth and the prevention of recurrence (Jonklaas et al. 2006, Brabant 2008, Goemann et al. 2017).

Over aggressive thyroxine (T4) therapy may lead to iatrogenic thyrotoxicosis, thus increasing the risk of atrial fibrillation (AF), mostly by increasing the heart rate (positive chronotropic effect) and conduction velocity (positive dromotropic effect). Impaired ventricular relaxation, the elevation of left atrial pressure due to increased left ventricular mass, ischaemia resulting from increased resting heart rate and re-entry might also be implicated in the development of AF (Shargorodsky et al. 2006, Bielecka-Dabrowa et al. 2009, Biondi \& Cooper 2010, Abdulrahman et al. 2011). In patients with endogenous hyperthyroidism (e.g. Graves' disease), low TSH levels are strongly related to AF risk (Camm et al. 2010). Therefore, it is reasonable to speculate that a similar relationship might exist in exogenous hyperthyroidism due to aggressive
THST. On the other hand, endogenous and iatrogenic thyrotoxicosis should not be considered as identical clinical states in terms of circulating thyroid hormones since free triiodothyronine (T3) levels (the ligand to nuclear thyroid receptors in the cell) differ between the two states. Different T3/T4 ratios might also be associated with different health outcomes (Biondi \& Cooper 2008).

In any case, if a high AF risk is confirmed in patients treated for DTC, then this might also increase the risk of stroke, heart failure and overall cardiovascular morbidity/ mortality, and could be of major concern, considering the favourable long-term prognosis of DTC (Biondi \& Cooper 2010, DeSantis et al. 2014, Carhill et al. 2015). Furthermore, RAI and in specific total cumulative dose might also be associated with the incidence of AF (Klein Hesselink et al. 2015). In other words, two independent predisposing factors to AF risk might be present in the management of DTC patients, while little is known about the magnitude of the effect (if any) and/or the individual patients' characteristics that might affect this risk.

To this end, we performed a systematic review and meta-analysis to assess for the first time the incidence of AF in DTC patients and collate it in reference to healthy controls.

\section{Methods}

The present systematic review followed the Preferred Reporting Items for Systematic reviews and Meta-Analyses (PRISMA) statement (Liberati et al. 2009). All research was conducted according to a protocol registered in OSF (Open Science Framework), available at: https://doi. org/10.17605/OSF.IO/YPCW7.

\section{Literature search strategy and study selection}

The bibliographic search (detailed in Table 1) was performed in the electronic databases Medline (via the PubMed platform), the Cochrane Central Register of Controlled Trials (CENTRAL) and clinicaltrials.gov. A basic search strategy was developed for PubMed and modified accordingly for other research engines. We also searched PROSPERO to check if any similar meta-analysis is in progress in order to avoid duplication with our study. Conference abstracts and references of relevant studies and systematic reviews were perused and experts were contacted in order to identify unpublished studies.

Records retrieved from the search were imported in reference management software. After removing the 
Table 1 MEDLINE search strategy.*

\begin{tabular}{lr}
\hline Search terms & Results \\
\hline 1. Arrhythmia (All Fields) & 240,499 \\
2. Atrial fibrillation (All Fields) & 77,853 \\
3. 1 OR 2 & 259,607 \\
4. Thyroid cancer (All Fields) & 75,780 \\
5. Thyroid neoplasm (All Fields) & 67,461 \\
6. Thyroid carcinoma (All Fields) & 71,642 \\
7. 4 OR 5 OR 6 & 78,956 \\
8. Exp animals/not humans.sh. & 263,760 \\
9. 3 AND 7 NOT 8 & 187 \\
10. Atrial fibrillation (Mesh) & 55,914 \\
11. Thyroid neoplasms (Mesh) & 52,823 \\
12. 10 AND 11 & 25 \\
\hline
\end{tabular}

*Via Pubmed, performed on 5 December 2019.

duplicate records, two reviewers (GK and ID) screened titles and abstracts independently and full texts were investigated for eligible studies. Differences in opinion between the two reviewers were resolved by a third reviewer (CA).

\section{Eligibility and exclusion criteria}

We included original case-control and cohort studies reporting estimates of the risk of incident $\mathrm{AF}$ in patients with DTC. There was no limitation in publication date or language. Pre-defined exclusion criteria were applied to the following studies: (i) with no original data (review articles, commentaries, editorials) or of case-series design, (ii) not reporting on incident AF rates, (iii) with less than 20 individuals, (iv) with unknown or less than 1-year duration of follow-up, (v) with no accessible or extractable data. A detailed summary of the excluded studies is presented in the flow chart (Fig. 1).

\section{Data extraction and quality assessment in individual studies}

Two reviewers ( $G$ K, I D) examined the search results and screened the titles and abstracts. Subsequently, full texts of the selected studies were obtained and evaluated independently by the two reviewers ( $G$ K, I D) for
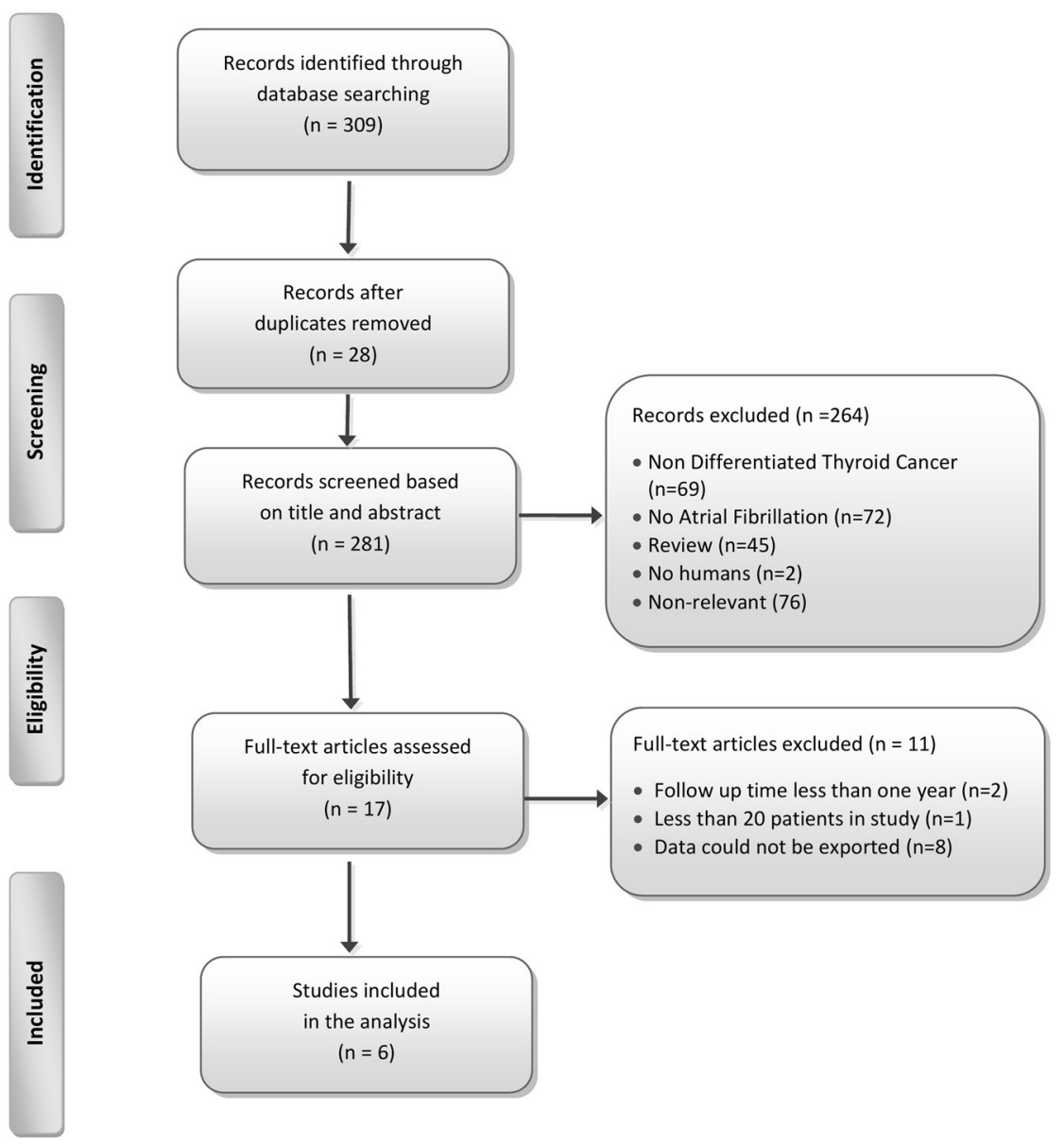

Figure 1

Summary of evidence search and selection.

https://erc.bioscientifica.com https://doi.org/10.1530/ERC-20-0496 (c) 2021 The authors Published by Bioscientifica Ltd. Printed in Great Britain
This work is licensed under a Creative Commons Attribution 4.0 International License.

ded from Bioscientifica.com at 04/26/2023 08:59:46AM 
eligibility. Any discordance regarding study eligibility was resolved by consultation with a senior author (K T). When necessary, we attempted to contact the study authors to clarify uncertainties in the study design or results.

Two reviewers (G K, I D) assessed the potential risk of bias in the included studies using the version of the Newcastle-Ottawa quality assessment scale (NOS) developed for case-control studies. On the basis of NOS quality assessment scale, a maximum of nine points was assigned for the least risk of bias in three domains: (i) selection of study groups (four points); (ii) comparability of groups (two points); (iii) ascertainment of exposure (three points) for case-control studies (http://www. ohri.ca/programs/clinical_epidemiology/oxford.asp). Any disagreement was resolved by discussion or by the involvement of a senior investigator $(\mathrm{K} \mathrm{T})$.

\section{Data synthesis and statistics}

The primary outcome was the aggregate incidence rate (IR) of AF in patients with DTC. Following Stijnen et al., we used a random effects (RE) generalized linear mixed model (GLMM) in pooling of individual studies (Stijnen et al. 2010, Schwarzer \& Chemaitelly 2019). Data referring to matched, cancer-free, control patients were also considered for quantitative synthesis. A pooled incidence rate ratio (IRR) estimate was calculated using a random effects GLMM model, as well. A prediction interval (PI) for the estimate of a new study was also calculated as proposed by Higgins (Higgins et al. 2009).The total number of person-years at risk, as reported by individual studies, was used. When these were not reported, the average length of follow-up and the total number of patients at the end of the study were used to approximate the total person-years (Pedder et al. 2016). In addition, to investigate sources of potential heterogeneity and to test the robustness of our results, a sensitivity analysis, incorporating studies with the highest quality, was conducted. A score of 9 points in the NOS quality assessment scale indicated a highest quality study. Analysis was performed in R v3.6.0 utilizing the meta package (Schwarzer 2007)

\section{Results}

\section{Search results and characteristics of the eligible studies}

The systematic literature search identified 281 potentially eligible articles; 6 studies finally met the eligibility criteria and were included in the review (Fig. 1). All included studies were observational in design and were conducted in Canada, the Netherlands, Finland, Korea, the United States and the United Kingdom between 2012 and 2019. Studies and patient characteristics are summarized in Table 2. Briefly, a total of 387,524 people were included in the studies of the meta-analysis: 187,754 patients with DTC and 199,770 healthy, cancer-free, matched controls with a follow-up time (mean or median) ranging from 4.3 to 19 years. The NOS scores of the studies were above 5 and presented in Table 3.

\section{Systematic review}

Four studies reported that the risk of incident AF was significantly higher in DTC patients compared to cancerfree controls, adjusted for established risk factors, such as age, hypertension, diabetes and coronary artery disease (Klein Hesselink et al. 2015, Pajamäki et al. 2018, Suh et al. 2019, Toulis et al. 2019), whereas another study reported a higher AF prevalence when compared to the general population (Abonowara et al. 2012). The sixth study included a cohort of DTC patients with low- and intermediate-risk for recurrence, examining the benefits of TSH suppression and potential skeletal and cardiovascular adverse events (Wang et al. 2015). In this study, the rate of AF was also reported. Overall, the IR for AF in DTC patients ranged from 2.2 to 9.36 per 1000 person-years; in those studies which included healthy controls, the adjusted hazard ratio (aHR) for AF in the DTC cohort ranged from 1.29 to 2.5 .

None of the included studies could provide evidence for a possible association between the aggressiveness of THST and the risk for AF, although indirect evidence was reported. Suh et al. reported that DTC patients were consistently found to be at a higher risk of developing AF across all categories of levothyroxine dosage, but the aHR was found to be highest in the highest dosage quartile, which might be indicative of a dose-response relationship (Suh et al. 2019). Of note, no correction for body weight was available. Finally, Pajamaki et al. reported that patients with TSH $<0.1 \mathrm{mU} / \mathrm{L}$ had an increased risk (HR: 1.27, CI:1.03-1.58) of cardiovascular morbidity mostly attributed to AF (Pajamäki et al. 2018).

The relation between RAI and incident AF was explored in a single study. Klein et al. reported that cumulative radioiodine dose might be correlated with a higher AF risk independently of TSH levels (Klein Hesselink et al. 2015). A subgroup analysis focusing on the patients treated with adjuvant RAI was also planned, but not conducted,

This work is licensed under a Creative Commons Attribution 4.0 International License. 


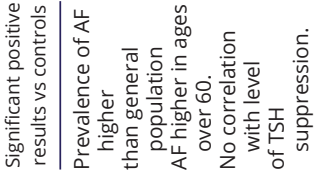
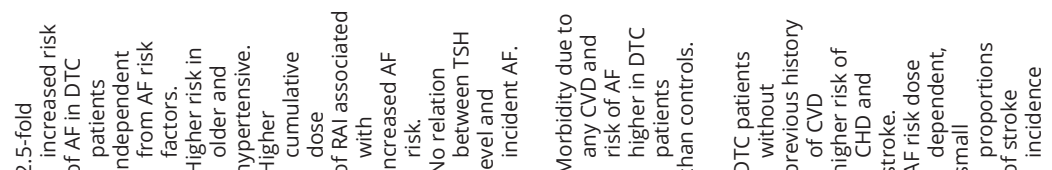

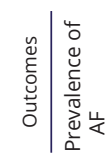

| I $\mid$

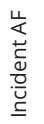

品

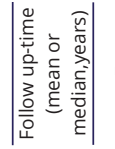

$\stackrel{\circ}{\circ}$

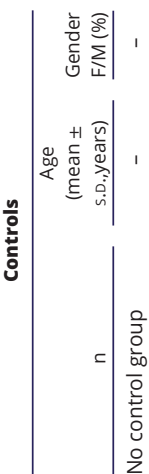

$\stackrel{\frac{1}{n}}{\stackrel{2}{2}}$

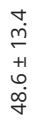

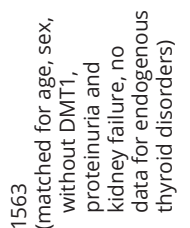

$\stackrel{\circ}{\circ}$

$\hat{\infty}$

$\bar{\varangle}$

$\bar{\varangle}$

f

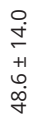

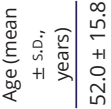

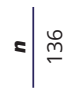

辛

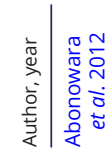

https://erc.bioscientifica.com

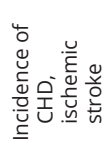

$\frac{\infty}{2}$

$\stackrel{*}{\%}$

$\bar{\infty} \underset{\infty}{\stackrel{\infty}{*}}$

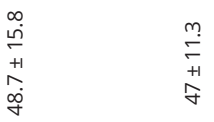

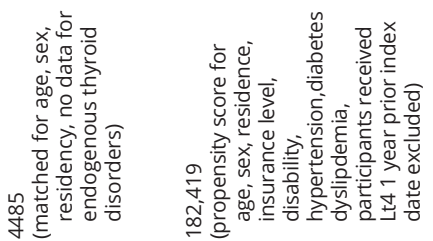

$\frac{\infty}{2}$

$\stackrel{*}{\substack{m \\ \wp}}$

$\frac{\grave{\infty}}{\stackrel{m}{\infty}}$

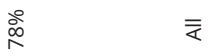

$\infty \quad \stackrel{\infty}{*}$

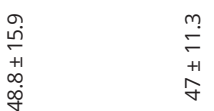

$\overline{2} \quad \stackrel{\substack{+\infty}}{\sim}$

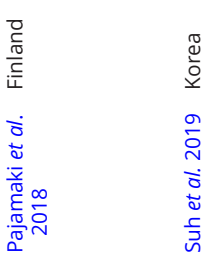

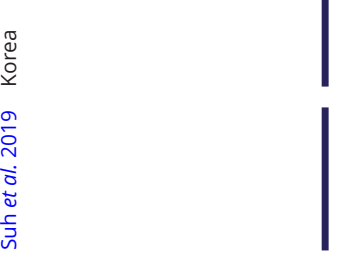

This work is licensed under a Creative Commons Attribution 4.0 International License.

ded from Bioscientifica.com at 04/26/2023 08:59:46AM 

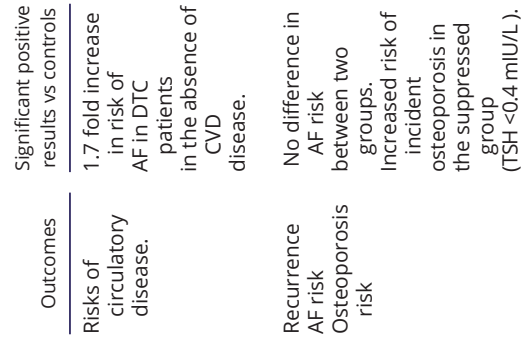

甹 $\mid \frac{\infty}{2}$

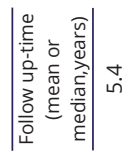

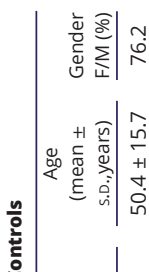
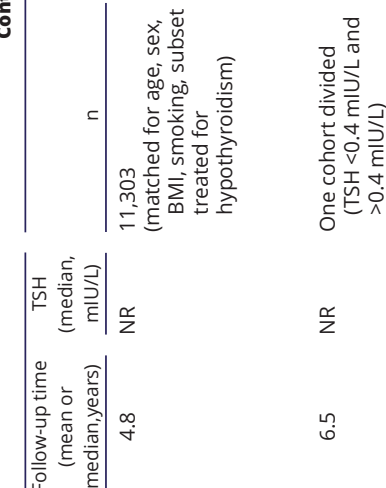

$\frac{\infty}{2}$

นึ้

হ)

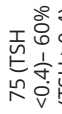

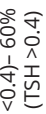

$\bar{\varepsilon}$

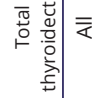

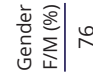

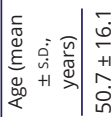

$\stackrel{\infty}{i}$

$\underset{\substack{+\infty \\+\infty}}{+\infty}$

$=\mid \begin{aligned} & \stackrel{\circ}{o} \\ & \dot{m}\end{aligned}$

$\Sigma$

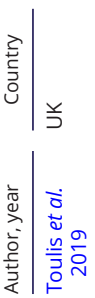

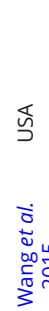

because data regarding incident $\mathrm{AF}$ in this cohort were not available.

In patients with DTC, the risk of AF was related significantly with older age and hypertension in two studies (Abonowara et al. 2012, Klein Hesselink et al. 2015). On the contrary, a large retrospective cohort study with 6900 Swedish DTC patients reported that DTC patients were at a higher risk of hospitalization for AF, especially those who were younger men and during the first 5 years of the follow-up time (Zoltek et al. 2020). This study was not included in our systematic review and meta-analysis as the primary outcome was the risk of hospitalization for AF and other cardiovascular endpoints. Only two studies involved patients without pre-existing circulatory disease, while one study was limited to low- and intermediate-risk patients (Wang et al. 2015, Suh et al. 2019, Toulis et al. 2019). Table 4 presents the event rate (AF) in patients with DTC and in healthy controls.

\section{Meta-analysis}

The overall IR of AF was estimated to be 4.86 (95\% CI, 3.29 to $7.17, \mathrm{I}^{2}=96 \%$, RE) cases per 1000 person-years (Fig. 2). Additionally, the pooled IRR of AF was equal to 1.54 (95\%CI, 1.44 to $1.65, \mathrm{I}^{2}=0 \%, 95 \% \mathrm{PI}, 1.33$ to 1.78 , RE) (Fig. 3). To further explore and address the issue of high heterogeneity among studies in our meta-analysis $\left(I^{2}=96 \%\right)$, a sensitivity analysis was undertaken including the highest quality observational studies $(\mathrm{NOS}=9)$ ) (Klein Hesselink et al. 2015, Pajamäki et al. 2018, Toulis et al. 2019). In this analysis, incident $A F$ was found to be 6.13 cases per 1000 person-years (95\% CI, 5.19 to 7.23 , $\mathrm{I}^{2}=40 \%$, RE), while the IRR of AF was 1.49 (95\%CI, 1.17 to $\left.1.89, \mathrm{I}^{2}=34 \%, \mathrm{RE}\right)$.

\section{Discussion}

In this study, the incidence of AF in patients with DTC by meta-analysis was found to be 4.86 cases per 1000 person-years. This estimate was based on studies with an adequate follow-up duration (mean follow-up $\geq 4.3$ years), considering that aggressive suppression therapy, when needed, is usually applied in the first 5 years after DTC diagnosis. To further quantify the magnitude of difference between patients with DTC and their healthy counterparts, we provided an IRR approximation, incorporating in parallel variations in the length of follow-up among studies. Our findings suggest that patients with DTC are 
Table 3 Detailed Newcastle-Ottawa score (NOS) grading for each study.

\begin{tabular}{l}
\hline Author,year \\
\hline Abonowara et al. 2012 \\
Klein Hesselink et al. 2015 \\
Pajamaki et al. 2018 \\
Suh et al. 2019 \\
Toulis et al. 2019 \\
Wang et al. 2015 \\
\hline
\end{tabular}

\begin{tabular}{c}
\hline Selection \\
\hline 2 \\
4 \\
4 \\
3 \\
4 \\
3 \\
\hline
\end{tabular}

expected to be at a higher risk for AF, namely about 50\%, compared to healthy controls (IRR $=1.54$ ).

In line with the European (Perros et al. 2014) and American guidelines (Haugen et al. 2016), long-term levothyroxine suppression following total thyroidectomy with or without adjuvant RAI is the recommended approach in patients with high-risk DTC. This intervention, aimed to prevent tumor recurrence, especially in the high and intermediate-risk group, leads to a state of iatrogenic hyperthyroidism. Endogenous hyperthyroidism is a well-known risk factor for AF, ischaemic stroke, angina, myocardial infarction and congestive heart failure in patients with underlying cardiovascular disease (Sawin et al. 1994, Ertek \& Cicero 2013). Similarly, overt and subclinical exogenous hyperthyroidism may also be associated with cardiovascular disease, including AF, diastolic dysfunction, and left ventricular hypertrophy (Shargorodsky et al. 2006, Biondi \& Cooper 2010, Abdulrahman et al. 2011).

In a meta-analysis of 8711 participants from 5 cohorts with a mean follow-up of 8.8 years, the estimated incidence of AF in patients with subclinical hyperthyroidism was 17.1 cases per 1000 person-years (Collet et al. 2012). Furthermore, Selmer et al. (2012) reported that incident AF in patients with overt and subclinical endogenous hyperthyroidism was 12.5 cases and 8.4 cases per 1000 person-years, respectively, based on a study population of 586,460 individuals. Finally, another large populationbased study from Norway (932,913 people) calculated that incident AF was $\sim 35.0$ cases per 1000 person-years within 3 months after the diagnosis of endogenous hyperthyroidism, declining to $\sim 9.3$ within 3 years of follow-up (Dekkers et al. 2017). The above findings suggest that the risk of AF is consistently elevated across different types of hyperthyroidism.

Patients with endogenous thyroid disease and a suppressed TSH are at a higher risk for AF. It is reasonable to anticipate a similar relationship in states of exogenous hyperthyroidism due to aggressive THST. Surprisingly, none of the included studies could demonstrate an association with AF and lower TSH values, either because

\begin{tabular}{c}
\hline Comparability \\
\hline 1 \\
2 \\
2 \\
2 \\
2 \\
1 \\
\hline
\end{tabular}

\begin{tabular}{c}
\hline Outcome \\
\hline 3 \\
3 \\
3 \\
3 \\
3 \\
3 \\
\hline
\end{tabular}

\begin{tabular}{c}
\hline Total \\
\hline 6 \\
9 \\
9 \\
8 \\
9 \\
7 \\
\hline
\end{tabular}

of the sample size (Abonowara et al. 2012), study design and number of events (Wang et al. 2015) or different TSH assays (Klein Hesselink et al. 2015). Another possible explanation is that many of these studies only analyse a single TSH measurement at single specific point-time during the patient follow-up, which is an inadequate measure of ongoing thyroid hormone status. Similarly, the single observation that total cumulative radioiodine dose might be an independent risk factor for AF has not been replicated.

Despite the observation that all the studies including controls reported a consistent increase in AF risk in patients with DTC relative to healthy counterparts, a notable variation in the reported IRs was observed, ranging from 2.2 to 7.08 in the DTC cohorts. This may be attributed to high heterogeneity (between-study variation) regarding baseline characteristics of the included population, sample size, follow-up time, definition and diagnosis of AF (paroxysmal, persistent, permanent, atrial flutterICD codes or $24 \mathrm{~h}$ Holter) and the aggressiveness of TSH suppression. More specifically, the lowest incidence rate was observed in a DTC cohort from Korea, which is in line with epidemiologic data regarding the global burden of AF (Chugh et al. 2014). Regional heterogeneity in the epidemiology of AF has been observed and reported in the literature and specifically, in Asia, lower AF incidence rates have been reported either because of sociodemographic factors or other factors (Chugh et al. 2014).

In addition, $\mathrm{AF}$ is associated with an increased risk of thromboembolic disease and therefore an increased incidence of ischemic cerebrovascular disease (Chugh et al. 2014). Since DTC patients are more likely to be diagnosed with $\mathrm{AF}$, it is plausible to assume that there is a similar tendency in incident stroke. However, the reports from two studies are conflicting. Toulis et al. (2019), found that DTC cohort had a modest risk increase for stroke or transient ischaemic attack, while Suh et al. (2019) found that a small number of ischaemic stroke events in the DTC patients were related to AF, although they were at a 2.5 -fold risk for other incident cerebrovascular disease.

This work is licensed under a Creative Commons Attribution 4.0 International License. ded from Bioscientifica.com at 04/26/2023 08:59:46AM 


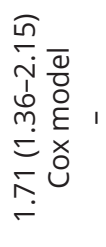

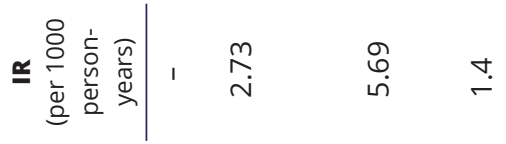

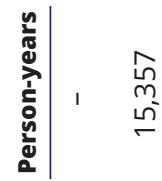

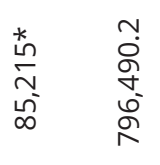

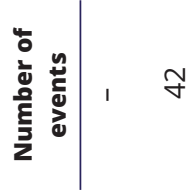

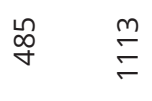

mे 1

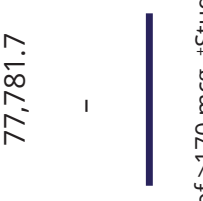

$\stackrel{n}{\leftarrow} \stackrel{m}{+}$

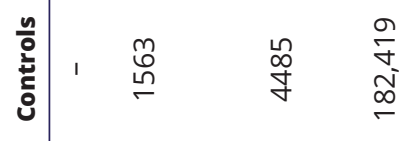

$\stackrel{\text { N }}{\text { N }}$

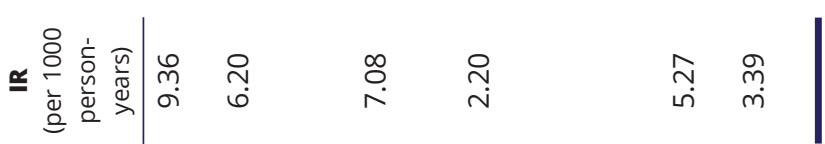

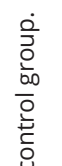




\section{Study}

Abonowara et al, 2012

Klein Hesselink et al, 2015

Pajamaki et al, 2018

Suh et al, 2019

Toulis et al, 2019

Wang et al, 2015

Random effects mode

Heterogeneity: $I^{2}=96 \%, \tau^{2}=0.2076$

$\begin{array}{rr}\text { Events } & \text { P-years } \\ & \\ 14 & 1496 \\ 35 & 5646 \\ 120 & 16939 \\ 1737 & 789756 \\ 102 & 19346 \\ 17 & 5012\end{array}$

\section{$\Gamma$}

Events per 1000 person-years
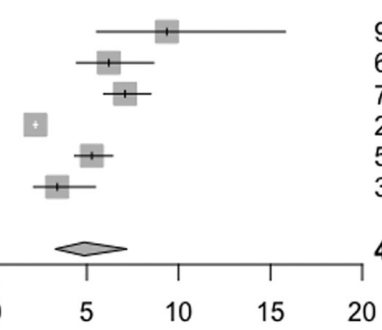

IR

$95 \% \mathrm{Cl}$

$9.36[5.54 ; 15.80]$

$6.20[4.45 ; 8.63]$

$7.08 \quad[5.92 ; 8.47]$

$2.20[2.10 ; 2.31]$

$5.27[4.34 ; 6.40]$

$3.39[2.11 ; 5.46]$

$4.86[3.29 ; 7.17]$

igure 2

Forest plot of aggregate IR of AF in patients with DTC.
From a clinical point of view, besides stroke prevention (prophylactic use of anticoagulants) a discrete approach might warrant further consideration in patients with iatrogenic hyperthyroidism regarding rhythm and rate control. Although there is no definite evidence that beta-blockers can prevent AF in subclinical hyperthyroidism, they may offer a reasonable option as a rate control intervention independently of the underlying disease, especially in patients with accompanying hypertension and heart failure, conditions that minimize Ic antiarrhythmics administration. On the other hand, amiodarone, an iodine-rich drug with a half-life of 100 days, is not recommended in those patients with DTC for whom RAI therapy is indicated since amiodarone interferes with 131 Iodine uptake for a long time after discontinuation and thus, RAI therapy or imaging is postponed if the patient has been treated with amiodarone within the previous year (Perros et al. 2014).

\section{Strengths and limitations}

To the best of our knowledge, this is the first attempt to provide an evidence-based estimate regarding the long-term effects of DTC treatment on the risk of AF. The strengths of our study include the comprehensive systematic search and the strict methodology regarding the identification of relevant studies and the selection process. Studies with unclear methodology or short follow-up time were excluded. On the other hand, we acknowledge that our meta-analysis had several limitations, including the observational and retrospective nature of the included studies, the high heterogeneity in study populations and baseline characteristics, the lack of data on the RAI cohort, thyroid function tests and discrepancies in AF definition and TSH assays. Such heterogeneity in population characteristics should be interpreted with caution in the context of generalizing the results of the present study to other settings. The results of our meta-analysis were largely attributable to the study conducted in Korea (Suh et al. 2019), which included over 350,000 participants. However, even with the exclusion of this study from the sensitivity analysis, the incidence of AF in patients with DTC stills remains significantly higher compared to controls. Moreover, lack of data regarding the histopathological type or disease stage and most importantly, the degree and aggressiveness of TSH suppression prevented any attempt to explore an association either of TSH suppression or cumulative RAI dose and development of AF and ischaemic cerebrovascular disease. Finally, since several AF cases are asymptomatic and, in some studies, the data were derived from primary care or claim databases, in which a diagnosis is matched to an ICD-10 code, the possibility that the true overall incidence rate might be underestimated cannot be precluded.

\section{Conclusion}

This is the first meta-analysis to confirm that patients with DTC are at a high risk for developing AF, which may be attributed to a state of iatrogenic hyperthyroidism due

\begin{tabular}{|c|c|c|c|c|c|c|}
\hline Study & Events & $\begin{array}{r}\text { DTC } \\
\text { P-years }\end{array}$ & Events & $\begin{array}{l}\text { Controls } \\
\text { P-Years }\end{array}$ & \multirow[t]{2}{*}{ Ratio } & $95 \% \mathrm{Cl}$ \\
\hline Klein Hesselink et al, 2015 & 35 & 5646 & 42 & 15357 & & $2.27[1.45 ; 3.55]$ \\
\hline Pajamaki et al, 2018 & 120 & 16939 & 485 & 85215 & $1-$ & $1.24[1.02 ; 1.52]$ \\
\hline Suh et al, 2019 & 1737 & 789756 & 1113 & 796490 & + & $1.57[1.46 ; 1.70]$ \\
\hline Toulis et al, 2019 & 102 & 19346 & 262 & 77782 & 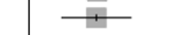 & $1.57[1.25 ; 1.97]$ \\
\hline Fixed effect model & & & & & $\diamond$ & \multirow{3}{*}{$\begin{array}{r}1.54[1.44 ; 1.65] \\
1.54[1.44 ; 1.65] \\
{[1.33 ; 1.78]}\end{array}$} \\
\hline Random effects model & & & & & $\diamond$ & \\
\hline Prediction interval & & & & & 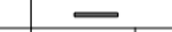 & \\
\hline \multirow[t]{2}{*}{ Heterogeneity: $I^{2}=0 \%, \tau^{2}=0$} & & & & Г & 1 & \\
\hline & & & & 0.5 & 1 & 4 \\
\hline
\end{tabular}

\section{Figure 3}

Forest plot of pooled IRR of AF in patients with DTC and their healthy, cancer-free controls https://erc.bioscientifica.com https://doi.org/10.1530/ERC-20-0496 (c) 2021 The authors Published by Bioscientifica Ltd. Printed in Great Britain
This work is licensed under a Creative Commons Attribution 4.0 International License. 
to thyrotropin suppression therapy. Hence, periodical screening for AF and its complications in selected cases might be considered.

\section{Declarations of interest}

All authors declare that there is no conflict of interest that could be perceived as prejudicing the impartiality of the research reported.

\section{Funding}

This research did not receive any specific grant from any funding agency in the public, commercial or not-for-profit sector.

\section{Author contribution statement}

G K: conceptualized the study design, performed the literature search, critically appraised the articles as first independent reviewer and formulated the paper. I D: conceptualized the study design, performed the literature search, critically appraised the articles as second independent reviewer, performed the statistical analysis. C A: critically appraised the paper, third independent reviewer. E B: performed the statistical analysis, critically appraised the paper. K N, D T, N T, G L: critically appraised the paper and made final suggestions. K T: conceived the idea, conceptualized the study design, supervised the statistical analysis, critically appraised the paper and made final suggestions. All authors approved the final version of the manuscript prior to submission.

\section{Acknowledgements}

The authors thank the reviewers for their constructive comments which greatly contributed to the improvement of the manuscript.

\section{References}

Abdulrahman RM, Delgado V, Hoftijzer HC, Ng AC, Ewe SH, Marsan NA, Holman ER, Hovens GC, Corssmit EP, Romijn JA, et al. 2011 Both exogenous subclinical hyperthyroidism and short-term overt hypothyroidism affect myocardial strain in patients with differentiated thyroid carcinoma. Thyroid 21 471-476. (https://doi. org/10.1089/thy.2010.0319)

Abonowara A, Quraishi A, Sapp JL, Alqambar MH, Saric A, O'Connell CM, Rajaraman MM, Hart RD \& Imran SA 2012 Prevalence of atrial fibrillation in patients taking TSH suppression therapy for management of thyroid cancer. Clinical and Investigative Medicine: Medecine Clinique et Experimentale 35 E152-E156. (https:// doi.org/10.25011/cim.v35i3.16591)

Bielecka-Dabrowa A, Mikhailidis DP, Rysz J \& Banach M 2009 The mechanisms of atrial fibrillation in hyperthyroidism. Thyroid Research 2 4. (https://doi.org/10.1186/1756-6614-2-4)

Biondi B \& Cooper DS 2008 The clinical significance of subclinical thyroid dysfunction. Endocrine Reviews 29 76-131. (https://doi. org/10.1210/er.2006-0043)

Biondi B \& Cooper DS 2010 Benefits of thyrotropin suppression versus the risks of adverse effects in differentiated thyroid cancer. Thyroid 20 135-146. (https://doi.org/10.1089/thy.2009.0311)

Brabant G 2008 Thyrotropin suppressive therapy in thyroid carcinoma: What are the targets? Journal of Clinical Endocrinology and Metabolism 93 1167-1169. (https://doi.org/10.1210/jc.2007-2228)
Carhill AA, Litofsky DR, Ross DS, Jonklaas J, Cooper DS, Brierley JD, Ladenson PW, Ain KB, Fein HG, Haugen BR, et al. 2015 Long-term outcomes following therapy in differentiated thyroid carcinoma: NTCTCS registry analysis 1987-2012. Journal of Clinical Endocrinology and Metabolism 100 3270-3279.(https://doi. org/10.1210/JC.2015-1346)

Chugh SS, Havmoeller R, Narayanan K, Singh D, Rienstra M, Benjamin EJ, Gillum RF, Kim YH, McAnulty JH, Jr, Zheng ZJ, et al. 2014 Worldwide epidemiology of atrial fibrillation: a Global Burden of Disease 2010 Study. Circulation 129 837-847. (https://doi. org/10.1161/CIRCULATIONAHA.113.005119)

Collet TH, Gussekloo J, Bauer DC, den Elzen WP, Cappola AR, Balmer P, Iervasi G, Asvold BO, Sgarbi JA, Volzke H, et al. 2012 Subclinical hyperthyroidism and the risk of coronary heart disease and mortality. Archives of Internal Medicine 172 799-809. (https://doi. org/10.1001/archinternmed.2012.402)

Davies L \& Welch HG 2014 Current thyroid cancer trends in the United States. Journl of the American Medical Association Otolaryngology: Head and Neck Surgery 140 317-322. (https://doi.org/10.1001/ jamaoto.2014.1)

Dekkers OM, Horvath-Puho E, Cannegieter SC, Vandenbroucke JP, Sorensen HT \& Jorgensen JO 2017 Acute cardiovascular events and all-cause mortality in patients with hyperthyroidism: a populationbased cohort study. European Journal of Endocrinology 176 1-9. (https://doi.org/10.1530/EJE-16-0576)

DeSantis CE, Lin CC, Mariotto AB, Siegel RL, Stein KD, Kramer JL, Alteri R, Robbins AS \& Jemal A 2014 Cancer treatment and survivorship statistics, 2014. CA: A Cancer Journal for Clinicians 64 252-271. (https://doi.org/10.3322/caac.21235)

Ertek S \& Cicero AF 2013 Hyperthyroidism and cardiovascular complications: a narrative review on the basis of pathophysiology. Archives of Medical Science 9 944-952. (https://doi.org/10.5114/ aoms.2013.38685)

European Heart Rhythm Association, European Association for CardioThoracic Surgery, Camm AJ, Kirchhof P, Lip GY, Schotten U, Savelieva I, Ernst S, Van Gelder IC, Al-Attar N, et al. 2010 Guidelines for the management of atrial fibrillation: the task force for the management of atrial fibrillation of the European Society of Cardiology (ESC). European Heart Journal 31 2369-2429. (https://doi. org/10.1093/eurheartj/ehq278)

Goemann IM, Romitti M, Meyer ELS, Wajner SM \& Maia AL 2017 Role of thyroid hormones in the neoplastic process: an overview. EndocrineRelated Cancer 24 R367-R385. (https://doi.org/10.1530/ERC-17-0192)

Haugen BR, Alexander EK, Bible KC, Doherty GM, Mandel SJ, Nikiforov YE, Pacini F, Randolph GW, Sawka AM, Schlumberger M, et al. 20162015 American Thyroid Association management guidelines for adult patients with thyroid nodules and differentiated thyroid cancer: the American Thyroid Association guidelines task force on thyroid nodules and differentiated thyroid cancer. Thyroid 26 1-133. (https://doi.org/10.1089/thy.2015.0020)

Higgins JP, Thompson SG \& Spiegelhalter DJ 2009 A re-evaluation of random-effects meta-analysis. Journal of the Royal Statistical Society: Series A 172 137-159. (https://doi. org/10.1111/j.1467-985X.2008.00552.x)

Jonklaas J, Sarlis NJ, Litofsky D, Ain KB, Bigos ST, Brierley JD, Cooper DS, Haugen BR, Ladenson PW, Magner J, et al. 2006 Outcomes of patients with differentiated thyroid carcinoma following initial therapy. Thyroid 16 1229-1242. (https://doi. org/10.1089/thy.2006.16.1229)

Klein Hesselink EN, Lefrandt JD, Schuurmans EP, Burgerhof JG, Groen B, Gansevoort RT, van der Horst-Schrivers AN, Dullaart RP, Van Gelder IC, Brouwers AH, et al. 2015 Increased risk of atrial fibrillation after treatment for differentiated thyroid carcinoma. Journal of Clinical Endocrinology and Metabolism 100 4563-4569. (https://doi.org/10.1210/jc.2015-2782) https://erc.bioscientifica.com https://doi.org/10.1530/ERC-20-0496 (c) 2021 The authors Published by Bioscientifica Ltd. Printed in Great Britain
This work is licensed under a Creative Commons Attribution 4.0 International License. ded from Bioscientifica.com at 04/26/2023 08:59:46AM 
Li M, Maso LD \& Vaccarella S 2020 Global trends in thyroid cancer incidence and the impact of overdiagnosis. Lancet: Diabetes and Endocrinology 8 468-470. (https://doi.org/10.1016/S22138587(20)30115-7)

Liberati A, Altman DG, Tetzlaff J, Mulrow C, Gøtzsche PC, Ioannidis JP, Clarke M, Devereaux PJ, Kleijnen J \& Moher D 2009 The PRISMA statement for reporting systematic reviews and meta-analyses of studies that evaluate healthcare interventions: explanation and elaboration. BMJ 339 b2700. (https://doi.org/10.1136/bmj.b2700)

Pajamäki N, Metso S, Hakala T, Ebeling T, Huhtala H, Ryödi E, Sand J, Jukkola-Vuorinen A, Kellokumpu-Lehtinen PL \& Jaatinen P 2018 Long-term cardiovascular morbidity and mortality in patients treated for differentiated thyroid cancer. Clinical Endocrinology 88 303-310. (https://doi.org/10.1111/cen.13519)

Pedder H, Sarri G, Keeney E, Nunes V \& Dias S 2016 Data extraction for complex meta-analysis (DECiMAL) guide. Systematic Reviews 5212. (https://doi.org/10.1186/s13643-016-0368-4)

Perros P, Boelaert K, Colley S, Evans C, Evans RM, Gerrard Ba G, Gilbert J, Harrison B, Johnson SJ, Giles TE, et al. 2014 Guidelines for the management of thyroid cancer. Clinical Endocrinology $\mathbf{8 1}$ (Supplement 1) 1-122. (https://doi.org/10.1111/cen.12515)

Rahbari R, Zhang L \& Kebebew E 2010 Thyroid cancer gender disparity. Future Oncology 6 1771-1779. (https://doi.org/10.2217/fon.10.127)

Sawin CT, Geller A, Wolf PA, Belanger AJ, Baker E, Bacharach P, Wilson PW, Benjamin EJ \& D'Agostino RB 1994 Low serum thyrotropin concentrations as a risk factor for atrial fibrillation in older persons. New England Journal of Medicine 331 1249-1252. (https://doi.org/10.1056/NEJM199411103311901)

Schwarzer G 2007 meta: an R package for meta-analysis. R News 7 40-45.

Schwarzer G, Chemaitelly H, Abu-Raddad LJ \& Rücker G 2019 Seriously misleading results using inverse of Freeman-Tukey double arcsine transformation in meta-analysis of single proportions. Research Synthesis Methods 10 476-483. (https://doi.org/10.1002/jrsm.1348)

Selmer C, Olesen JB, Hansen ML, Lindhardsen J, Olsen AM, Madsen JC, Faber J, Hansen PR, Pedersen OD, Torp-Pedersen C, et al. 2012 The spectrum of thyroid disease and risk of new onset atrial fibrillation: a large population cohort study. BMJ 345 e7895. (https://doi. org/10.1136/bmj.e7895)

Shargorodsky M, Serov S, Gavish D, Leibovitz E, Harpaz D \& Zimlichman R 2006 Long-term thyrotropin-suppressive therapy with levothyroxine impairs small and large artery elasticity and increases left ventricular mass in patients with thyroid carcinoma. Thyroid $\mathbf{1 6}$ 381-386. (https://doi.org/10.1089/thy.2006.16.381)

Stijnen T, Hamza TH \& Ozdemir P 2010 Random effects meta-analysis of event outcome in the framework of the generalized linear mixed model with applications in sparse data. Statistics in Medicine 29 3046-3067. (https://doi.org/10.1002/sim.4040)

Suh B, Shin DW, Park Y, Lim H, Yun JM, Song SO, Park JH, Cho B \& Guallar E 2019 Increased cardiovascular risk in thyroid cancer patients taking levothyroxine: a nationwide cohort study in Korea. European Journal of Endocrinology 180 11-20. (https://doi.org/10.1530/ EJE-18-0551)

Toulis KA, Viola D, Gkoutos G, Keerthy D, Boelaert K \& Nirantharakumar K 2019 Risk of incident circulatory disease in patients treated for differentiated thyroid carcinoma with no history of cardiovascular disease. Clinical Endocrinology 91 323-330. (https:// doi.org/10.1111/cen.13990)

Viola D, Valerio L, Molinaro E, Agate L, Bottici V, Biagini A, Lorusso L, Cappagli V, Pieruzzi L, Giani C, et al. 2016 Treatment of advanced thyroid cancer with targeted therapies: ten years of experience. Endocrine-Related Cancer 23 R185-R205. (https://doi.org/10.1530/ ERC-15-0555)

Wang LY, Smith AW, Palmer FL, Tuttle RM, Mahrous A, Nixon IJ, Patel SG, Ganly I, Fagin JA \& Boucai L 2015 Thyrotropin suppression increases the risk of osteoporosis without decreasing recurrence in ATA low- and intermediate-risk patients with differentiated thyroid carcinoma. Thyroid 25 300-307. (https://doi.org/10.1089/ thy.2014.0287)

Zoltek M, Andersson TM, Hedman C, Ihre-Lundgren C \& Nordenvall C 2020 Cardiovascular incidence in 6900 patients with differentiated thyroid cancer: a Swedish nationwide study. World Journal of Surgery 44 436-441. (https://doi.org/10.1007/s00268-019-05249-8)

Received in final form 22 March 2021

Accepted 31 March 2021

Accepted Manuscript published online 31 March 2021 (c) 2021 The authors Published by Bioscientifica Ltd. Printed in Great Britain
This work is licensed under a Creative Commons Attribution 4.0 International License.

ded from Bioscientifica.com at 04/26/2023 08:59:46AM 